\title{
Cerita gambar wisata kuliner seru bersama sahabat buah: media alternatif edukasi pemilihan jajanan sehat
}

\section{Septian Emma Dwi Jatmika*, Farikhah Nur Laila, Mufidatusholihah, Ravika Andinie, Fitri Rekyan MWH}

a Fakultas Kesehatan Masyarakat, Universitas Ahmad Dahlan

${ }^{1}$ septianemma@ikm.uad.ac.id

*Correspondent Author

\section{ARTICLE INFO}

\section{Article history}

Received 25 Januari 2021

Revised 11 Februari 2021

Accepted 23 Februari 2021

Keywords

Healthy culinary

Knowledge

Media

Picture book

\section{ABSTRACT}

Children often have problems with snacks. They need health education to be able to choose healthy foods to meet optimal nutritional intake. This study aims to see the effect of using picture book media on increasing knowledge about healthy culinary tourism at Elementary School Gedongkiwo Yogyakarta. This type of study is quasiexperimental research. The survey designed is One Group Pretest Post Test Design. The reserch participants were 25 grade 2 elementary school students. The data analysis technique used the Paired Sample TTest statistical test. The result obtained is that picture books do not affect knowledge about healthy culinary tourism ( $p$-value $0.770>$ $0.05)$. A total of 9 students experienced a decrease in their level, seven students experienced an increase, and nine students did not experience a reduction or increase in knowledge. It is possible because the method used is combining lectures with visual story media during class. The conditions are different if students read pictorial stories themselves during leisure time. The next researcher will be able to study using a more simple method, for example, while having group discussions so that there is a two-way exchange of information.

This is an open-access article under the CC-BY-SA license.

\section{Pendahuluan}

Salah satu hak dasar manusia adalah keamanan pangan dan ketersediaannya. Saat ini ratusan juta manusia menderita penyakit karena keracunan pangan. Anak sekolah adalah kelompok yang paling rentan terkena masalah keracunan pangan. Pada Tahun 2007 Badan Pengawas Obat dan Makanan (BPOM) melakukan survey bahwa 45\% jajanan anak sekolah berbahaya (1). Orangtua dan guru perlu memperhatikan terkait dengan masalah jajanan pada anak sekolah karena berisiko terhadap cemaran sehingga dapat mengganggu kesehatan. Hal ini terlihat pada sampel makanan yang telah dilakukan uji yaitu masih adanya kandungan boraks dalam jajanan tersebut sebanyak $8 \%$, formalin $67 \%$ dan 11 sampel jajanan tercemar bakteri coliform. Ada 2 sampel jajanan yang melewati syarat mutu SNI-3788-2009 tentang batas maksimum cemaran mikroba dalam makanan (2). Asupan gizi diperlukan untuk anak sekolah. Hal tersebut bisa didapat dari makanan/jajanan yang baik untuk menunjang aktivitas sehari-hari anak sekolah. Selain memiliki aktivitas yang tinggi, zat gizi yang baik berguna untuk memenuhi kebutuhan pertumbuhan badan anak. Mereka perlu mengonsumsi makanan saat disekolah seperti snack/makanan ringan supaya kadar gula darah tetap stabil. Hal ini akan berdampak baik pada konsentrasi anak saat menerima 
pelajaran(3). Banyaknya jajanan yang dijajakan membuat anak rentan terpengaruh untuk jajan sembarangan. Berbagai macam jajanan biasanya dijual di lingkungan sekolah. Masih banyak anakanak yang belum membiasakan diri untuk membawa bekal ke sekolah, masih jajan sembarangan yang banyak mengandung pengawet, pewarna, dan penambah cita rasa.Penelitian sebelumnya yang dilakukan di Sekolah Dasar Negeri Sonosewu Yogyakarta sebanyak 42\% anak-anak memiliki kebiasaan sering jajan di sekolah (4).

Penyampaian pesan kesehatan perlu diberikan secara terus menerus pada anak. Dalam memberikan informasi pada anak perlu strategi khusus agar menarik dan anak tidak bosan. Penggunaan media diperlukan dalam hal ini. Media merupakan suatu bentuk yang digunakan untuk menyalurkan pesan informasi. Pengembangan satu media akan memengaruhi efektifitas dalam menyampaikan pesan saat proses belajar. Media juga tidak hanya pesan tertulisa saja, namun dapat berbentuk gambar seperti cergam atau cerita bergambar. Sebuah penelitian menyebutkan bahwa ada peningkatan rata-rata tingkat pengetahuan anak sekolah dari sebelumnya 4,82 menjadi 6,99 setelah diberikan edukasi dengan buku cerita bergambar (5). Media buku cerita bergambar akan mendorong minat siswa dalam hal membaca dan rasa ingin tahu yang tinggi terhadap pokok bahasan yang akan disampaikan. Kombinasi antara gambar dan tulisan yang disesuaikan dengan materi dan disusun secara menarik akan membuat siswa tidak merasa jenuh dalam membaca. Pengembangan buku cerita bergambar layak digunakan dan dapat meningkatkan minat membaca bagi anak sekolah dasar (6). Belum banyaknya media pembelajaran berupa buku cerita bergambar mendorong peneliti melakukan penelitian pengembangan ini. Buku cerita bergambar difokuskan untuk siswa SD Kelas 1 dan 2. Mendeskripsikan permasalahan jajanan yang tidak sehat yang banyak dikonsumsi anak dan upaya penanggulangannya. Media buku cerita bergambar bertujuan untuk meningkatkan pengetahuan anak, orang tua dan guru tentang jajanan sehat bagi anak dan pentingnya makan buah dan sayur bagi pertumbuhan anak (7).

Fakta lain dari persoalan makanan jajanan adalah menyangkut sanitasi makanan. Dari hasil observasi di Yogyakarta, dari 40 pedagang makan jajanan anak sekolah didapatkan hasil bahwa sebanyak $85 \%$ pedagang makanan jajanan memiliki perilakunya kurang baik terakait dengan hygiene dan sanitasi makanan sehingga berpotensi dapat mengontaminasi makanan (8). Selain itu persoalan terkait dengan keamanan makanan jajanan. Dilihat dari segi keamanan, persentase makanan jajanan anak SD yang mengandung boraks, formalin, dan rhodamin-B masih tinggi. Dari ketiga zat berbahaya tersebut frekuensi kemunculan kandungan rhodamin-B adalah yang paling tinggi sebesar 46,7\%. Konsumsi rhodamin-B yang berlebihan berdampak pada gangguan kesehatan. Berbagai gangguan kesehatan tersebut seperti gangguan fisiologis tubuh, kerusakan hati, gejala pembesaran hati dan ginjal, gangguan fungsi hati atau bahkan bisa menyebabkan timbulnya kanker hati (9). Observasi yang dilakukan oleh peneliti didapatkan data bahwa masih banyak penjual makanan yang tidak sehat. Mereka masih banyak menggunakan berbagai macam bahan makanan tambahan yaitu 3M (pemanis, pewarna, dan pengawet). Ada beberapa anak yang tidak jajan karena sudah dibawakan bekal orangtuanya. Ada juga yang masih jajan dengan alasan karena diberi uang saku oleh orangtuanya. Dua orang anak sekolah mengatakan bahwa sering jajan meski sudah dibawakan bekal oleh tuanya. Berdasarkan penjelasan diatas, penelitian ini bertujuan untuk melihat pengaruh penggunaan media buku cerita bergambar terhadap peningkatan pengetahuan tentang jajanan sehat di SD Negeri Gedongkiwo Yogyakarta. Media tersebut disusun oleh peneliti sendiri. Diawali dengan penyusunan alur cerita kemudian dituangkan dalam bentuk gambar. Penelitian ini bermanfaat untuk memberikan informasi kepada anak, orang tua, dan guru tentang makanan atau jajanan yang tidak sehat bagi anak.

\section{Metode}

Metode penelitian yang digunakan yaitu Quasi eksperimental dengan rancangan One Group Pre tes Post Test Design. Penelitian dilakukan di SD Negeri Gedongkiwo Yogyakarta pada Juni 2019. Populasi penelitian adalah siswa/i kelas II SD Negeri Gedongkiwo berjumlah 25 siswa dan 
seluruhnya dijadikan subjek penelitian. Intervensi dilakukan dengan cara memberikan edukasi menggunakan media cerita bergambar sebanyak 1 kali pertemuan pada pagi hari sebelum proses pembelajaran dilakukan. Peneliti memberikan kuesioner untuk dijawab secara tertulis oleh siswa sebelum dan sesudah intervensi. Instrumen penelitian yang digunakan adalah kuisioner pengetahuan tentang jajanan sehat $(3 \mathrm{P})$. Ada 14 pertanyaan dalam kuesioner. Kemudian diolah untuk melihat skor pengetahuan. Pengambilan data dilakukan dengan melakukan dua kegiatan yaitu pengisian kuesioner saat sebelum diberikan intervensi menggunakan media cerita bergambar dan setelah diberikan intervensi. Peneliti melakukan pengawasan saat anak-anak mengisi kuesioner agar siswa mengerjakan sendiri pre test dan post test. Setelah selesai kuesioner langsung dikembalikan pada peneliti (lihat gambar 1).
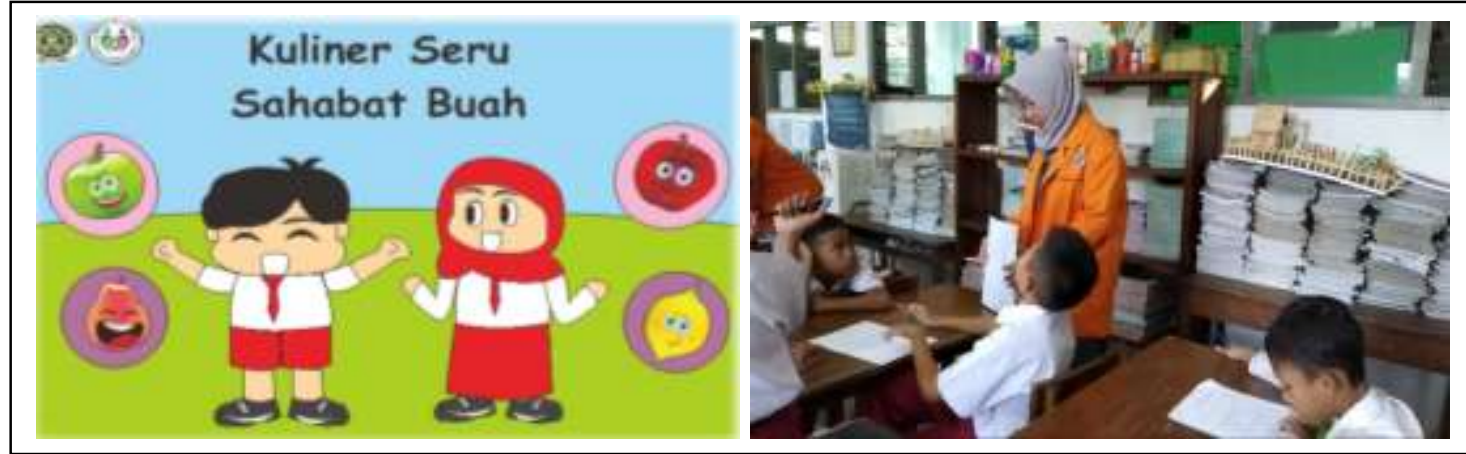

Gambar 1. buku cerita bergambar kuliner seru sahabat buah dan suasana intervensi menggunakan cerita bergambar

Teknik analisis data dengan menggunakan uji statistik paired sample $t$ test. Analisis Univariat dimaksud untuk mendeskripsikan karakteristik responden dan melihat perubahan rerata. Analisis Bivariat dalam penelitian ini untuk mengetahui pengaruh intervensi media cerita bergambar terhadap peningkatan pengetahuan siswa mengenai jajanan sehat saat berwisata kuliner. Uji paired sampe t test bertujuan untuk menguji perbedaan antara dua kelompok data yang dependen (10).

\section{Hasil dan Pembahasan}

Penelitian dilaksanakan pada tanggal 18 Juni 2019. Lebih dari separoh siswa yang menjadi responden berjenis kelamin perempuan (60\%). Karakteristik responden dapat terlihat pada table 1.

Tabel 1. Disribusi Frekuensi Karakteristik Responden

\begin{tabular}{lcc}
\hline \multicolumn{1}{c}{ Jenis Kelamin } & Frekuensi (org) & Persentase (\%) \\
\hline Siswa laki-Laki & 10 & 40 \\
Siswa perempuan & 15 & 60 \\
Total & 25 & 100 \\
\hline
\end{tabular}

Intervensi dilakukan dengan memberikan edukasi tentang pemilihan jajanan sehat menggunakan media cerita bergambar yang dibuat sendiri oleh peneliti melalui penelitian research and development. Materi cerita bergambar berisi tentang makanan sehat dan aman sesuai dengan standar 3P (Pewarna, pengawet, dan perasa). Media cerita bergambar dirancang berdasarkan penelitian sebelumnya yang mengatakan bahwa salah satu faktor yang berhubungan dengan pemilihanan jajanan anak adalah pengetahuan (11). Dari penelitian sebelumnya juga 
masih banyak didapati anak sekolah yang pemilihan jajanan serta pengetahuan dan sikapnya tidak baik. Padahal itu dapat beresiko terhadap kerusakan organ pencernaan (12). Menurut penelitian Nurul Iklima ada 64,5\% yang memiliki kebiasaan jajan sembarangan/tidak baik. Sebanyak 93,6\% makanan yang dipilih banyak terkandung didalamnya penambah rasa yang berlebihan sehingga terasa sangat gurih. Anak sekolah menganggapnya bahwa rasa lebih penting dari gizi yang seharusnya dibutuhkan, padahal ada dampak buruk yang ditimbulkan seperti kerusakan pada organ pencernaan (13).

Anak sekolah perlu dibekali pengetahuan tentang pemilihan jajanan agar dapat memilih jajanan yang sehat dan bergizi. Hasil penelitian Adipta tentang pemanfaatan buku cerita bergambar sebagai sumber bacaan di SDN Sukoharjo 2 sudah cukup optimal. Dari hasil tersebut terlihat bahwa yang banyak memanfaatkan buku cerita bergambar adalah anak kelas 1 sampai 3 sekolah dasar (7). Media cerita bergambar sangat disukai oleh anak-anak SD. Penelitian lain juga didapatkan hasil bahwa buku cerita bergambar efektif sebagai pembelajaran bagi siswa sekolah dasar (14). Uji kelayakan terbatas media cerita bergambar dilakukan pada penelitian ini dengan cara mengintervensi siswa melalui edukasi menggunakan media cerita bergambar yang telah dibuat. Caranya adalah siswa diminta untuk duduk berkelompok dan peneliti memberikan edukasi dengan cara membacakan cerita bergambar wisata kuliner jajanan sehat. Siswa diminta untuk memperhatikan dan menanggapi cerita yang disampaikan. Pada keadaan ini siswa sedikit ramai karena banyak yang tidak sabar untuk membaca sendiri buku cerita bergambar. Selanjutnya siswa diminta untuk berdiskusi menceritakan pengalaman apa saja yang mereka ketahui tentang makanan sehat.

Dalam penelitian ini peneliti memberikan pre-test terlebih dahulu, dilanjutkan dengan pemberian intervensi berupa edukasi dengan menggunakan media pembelajaran cerita bergambar: "kuliner seru sahabat buah". Setelah itu diberikan soal post-test untuk mengetahui pengaruh dari media pembelajaran yang telah diberikan. Hasil uji normalitas data pada table 2 . adalah data berdistribusi normal dengan $\mathrm{p}>0,05$. Rata-rata pre-test dan post-test yaitu 9,24 menjadi 9,44. Dilihat dari rata-rata sebelum dan sesudah dilakukan tes ada kenaikan nilai ratarata responden. Selanjutnya dilakukan uji Paired t-Test. Hasil uji Paired t-Test $p$ value 0,770 atau $>0,05$. Peneliti simpulkan bahwa tidak ada pengaruh inteervensi pemberian edukasi dengan media cerita bergambar terhadap peningkatan pengetahuan siswa tentang makanan sehat saat berwisata kuliner.

Tabel 2. Hasil Uji Paired t-Test

\section{Pre Test Post Test}

Mean Pre Test
9,24

Mean Post Test 9,44
Sig (p value)

0,770

Dalam melakukan edukasi kesehatan menggunakan metode ceramah ada kelebihan dan kekurangannya. Metode ceramah lebih mudah dilakukan tetapi jika digunakan terlalu lama audience akan merasa bosan. Hal ini menyebabkan anak-anak juga menjadi pasif(15). Penerapan metode ceramah juga mempunyai kelemahan lainnya yaitu ada unsur paksaan terhadap peserta didik, adanya sedikit daya kritis peserta didik, lebih sulit diterima pada peserta didik dengan gaya belajar visual daripada peserta didik dengan gaya belajar audio, susah menilai pemahaman peserta didik sejauh mana, kegiatan pengajaran menjadi verbalisme, peserta didik merasa jenuh apabila terlalu lama (16). Penelitian terdahulu yang juga mengintervensi anak sekolah dasar dengan metode ceramah didapatkan hasil bahwa tidak ada perbedaan pengetahuan tentang cuci tangan sebelum dan sesudah diberi penyuluhan (17). Sebaliknya penelitian media edukasi gizi yang dilakukan oleh Astuti (18) menemukan adanya peningkatan rata-rata pre-test $(47,11)$ menjadi post-test $(71,05)$. Adanya peningkatan pengetahuan $50,8 \%$. Adanya perbedaan ini dapat terjadi karena pada saat pemberian penyuluhan terdapat kendala dan hambatan media, siswa kurang memperhatikan sehingga informasi yang diterima tidak seluruhnya diserap oleh siswa, 
lingkungan, dll. Untuk melihat pada tabel Ranks jumlah peningkatan, penurunan skor ataupun yang tidak mengalami keduanya dilakukan Uji Wilcoxon. Hasil dapat dilihat pada Tabel 3.

Tabel 3. Hasil Ranks pada Uji Wilcoxon

\begin{tabular}{llc}
\hline & & N (orang) \\
\hline Pre Test Post Test & Negative Ranks (Post Test < Pre Test) & 9 \\
& Positive Ranks (Post Test > Pre Test) & 7 \\
& Ties (Post Test = Pre Test) & 9 \\
& Total & 25 \\
\hline
\end{tabular}

Hasil uji Wilcoxon di atas didapatkan bahwa dari 25 siswa didapatkan sebanyak 9 siswa mengalami penurunan tingkat pengetahuan, 7 siswa mengalami peningkatan pengetahuan, dan 9 siswa tidak mengalami penurunan atau peningkatan pengetahuan. Pada saat pelaksanaan penelitian berlangsung, siswa cenderung bosan dan tidak fokus karena siswa hanya duduk diam mendengarkan penjelasan. Terlebih lagi suasana yang kurang kondusif di dalam kelas dan tempat duduk yang jaraknya tidak diatur sedemikian rupa. Hal ini sesuai dengan teori kelemahan metode ceramah yang telah disebutkan sebelumnya dan juga pada penelitian yang telah dilakukan oleh Eka Putri bahwa siswa yang diajar menggunakan metode problem solving hasil belajar yang didapatkan lebih tinggi dibanding yang menggunakan metode ceramah (18). Pada penelitian yang sudah dilakukan oleh Afif bahwa adanya perbedaan yang didapatkan pada saat melakukan ceramah menggunakan media buku cerita bergambar dengan media permainan ular tangga. Hasil yang didapatkan dalam penelitian ini bahwa menggunakan permainan ular tangga dapat lebih efektif dalam meningkatkan pengetahuan dan sikap serta praktik menggosok gigi dengan benar pada anak sekolah dasar. Pada penelitian tersebut didapatkan hasil bahwa metode ceramah dapat efektif tetapi dengan metode lain seperti permainan. Sehingga anak-anak lebih aktif dan cenderung tidak menimbulkan kebosanan pada anak (19).

Selain media buku cerita bergambar, ada media lain yang juga dapat digunakan untuk memberikan edukasi kesehatan pada anak. Penelitian yang dilakukan di SD N 2 Patrang Jember. Hasil dari penelitian tersebut menemukan pendidikan kesehatan menggunakan media ular tangga lebih efektif dibandingkan menggunakan buku cerita bergambar. Metode permainan yang digunakan dalam kegiatan pembelajaran lebih disukai oleh siswa SD. Siswa menyukai media dalam kegiatan pembelajaran yang bersifat memberi permainan yang menyenangkan karena kondisi psikologis anak-anak yang masih senang bermain membuat belajar sambil bermain tidak akan membosankan dibandingkan dengan metode ceramah yang boleh dikatakan sebagai metode tradisional (20).

\section{Kesimpulan}

Pemanfaatan buku cerita bergambar sebagai media promosi wisata kuliner sehat cukup membuat anak-anak tertarik pada penggunaan media. Hasil pengujian pemberian edukasi dengan media cerita bergambar tidak ada pengaruh, kemungkinan ini disebabkan karena peneliti menggabungkan metode ceramah dengan penggunaan media cerita bergambar pada saat pelaksanaan pemberian intervensi sehingga kurang menarik perhatian siswa. Penelitian ini diharapkan dapat memberi motivasi bagi guru di sekolah dan orangtua/wali santri untuk bisa mengedukasi siswa agar tidak jajan sembarangan dan lebih memilih untuk jajanan yang sehat. Cara yang digunakan peneliti selanjutnya dapat dengan mengkombinasikan penggunaan cergam dan menggunakan metode diskusi dengan anak-anak agar terjadi pertukaran informasi secara dua arah. 


\section{Ucapan Terimakasih}

Penulis mengucapkan terimakasih kepada dekan Fakultas Kesehatan Masyarakat yang telah mensupport artikel ini.

\section{Konflik Kepentingan}

Tidak ada konflik kepentingan.

\section{Referensi}

1. BPOM. Sistem Keamanan Pangan Terpadu Jajanan Anak Sekolah. 2009.

2. Anton L, Yearsi SEN, Habibi M. Identifikasi Kandungan Berbahaya Jajanan Anak Sekolah Dasar SDN A dan SDN B Kota Samarinda Tahun 2018. Kesmas Uwigama J Kesehat Masy. 2019;5(1).

3. BPOM. Pedoman Pangan Janjanan Anak Sekolah untuk Pencapaian Gizi Seimbang. In Jakarta: DIREKTORAT STANDARDISASI PRODUK PANGAN DEPUTI BIDANG PENGAWASAN KEAMANAN PANGAN DAN BAHAN BERBAHAYA BADAN PENGAWAS OBAT DAN MAKANAN REPUBLIK INDONESIA; 2013.

4. Noviani K, Afifah E, Astiti D. Kebiasaan jajan dan pola makan serta hubungannya dengan status gizi anak usia sekolah di SD Sonosewu Bantul Yogyakarta. J Gizi dan Diet Indones. 2016;4(2).

5. Oktarina ND, Liyanovitasari. Pengaruh Media Cerita Bergambar terhadap Pengetahuan tentang Seks Dini pada Anak. J Kesehat Perintis (Perintis's Heal Journal). 2019;6(2).

6. Apriliani SP, Radia EH. Pengembangan Media Pembelajaran Buku Cerita Bergambar untuk Meningkatkan Minat Membaca Siswa Sekolah Dasar. J Basicedu. 2020;4(4).

7. Adipta H, Maryaeni, Hasanah Muakibatul. Pemanfaatan Buku cerita Bergambar Sebagai Sumber Bacaan Siswa SD. J Pendidik Teor , Penelitian, dan Pengemb. 2016;1(5):989-92.

8. Kahlasi HB, Febriani H, Chasanan SU. Higiene Sanitasi Pedagang dengan Perilaku Pedagang Makanan Jajanan di Sekolah Dasar Kecamatan Banguntapan Bantul Yogyakarta. J Med Respati. 2019;14(3).

9. Paratmanitya Y, Aprilia V. Kandungan bahan tambahan pangan berbahaya pada makanan jajanan anak sekolah dasar di Kabupaten Bantul. J Gizi dan Diet Indones. 2016;4(1).

10. Sabri L, Hastono SP. Statistik Kesehatan. Depok: PT RajaGrafindo Persada; 2014. 120 p.

11. Hatta H, Hadi AJ, Yetti R E, Tombeg Z, Manggabarani S. Hubungan Faktor Pemilihan Makanan Jajanan Siswa di Sekolah Dasar Inpres Maccini Sombala Kota Makassar. Wind Heal J Kesehat. 2018;1(4).

12. Syam A, Indriasari R, Ibnu I. Gambaran Pengetahuan dan Sikap Siswa terhadap Makanan Jajanan Sebelum dan Setelah Pemberian Edukasi Kartu Kwartet Pada Anak Usia Sekolah Dasar di Kota Makassar. J TEPAT Teknol Terap untuk Pengabdi Masy. 2018;1(2).

13. Iklima N. Gambaran Pemilihan Makanan Jajanan Pada Anak Usia Sekolah Dasar. J Keperawatan BSI. 2017;5(1).

14. Dessiane ST, Hardjono N. Efektivitas Media Pembelajaran Cerita Bergambar Atau Komik Bagi Siswa Sekolah Dasar. J Pendidik dan Konseling. 2020;2(1).

15. Hermawati L, Sukirman, Ivada E. Upaya Meningkatkan Keaktifan Belajar dan Hasil Belajar Akuntansi dengan Strategi Pembelajaran Aktif Learning Tournament pada Siswa Kelas X AK 2 SMKN 3 Surakarta Tahun Ajaran 2013/2014. JUPE UNS. 2014;2(3):273-83. 
16. H Simamora R. Buku Ajar Pendidikan dalam Keperawatan. Jakarta: Penerbit Buku Kedokteran EGC; 2009.

17. Rastini NK, Marwati NM. Perbedaan Penggunaan Metode Ceramah dengan Metode Ceramah Kombinasi Media Video terhadap Pengetahuan dan Tindakan Cuci Tangan Pakai Sabun Siswa. J Kesehat Lingkung. 2018;8(1):13-22.

18. Astuti NB, Sari EP, Felle GM. Buku Cerita dan Buku Saku sebagai Media Edukasi Gizi untuk Meningkatkan Pengetahuan Sayur dan Buah. J Gema Kesehat. 2019;11(1).

19. Putri E. Perbedaan Hasil Belajar Ekonomi Menggunakan Metode Problem Solving (Pemecahan Masalah) dengan Metode Ceramah pada Siswa Kelas X IPS SMA N 3 Teladan Bukittinggi. J Pendidik Ekon. 2018;11(2).

20. Hamdalah A. Efektivitas Media Cerita Bergambar dan Ular Tangga Dalam Pendidikan Kesehatan Gigi dan Mulut Siswa Sdn 2 Patrang Kabupaten Jember. J Promkes. 2013;1(2):11823. 